\title{
Manajemen Pemetikan Tanaman Teh (Camelia Sinensis (L) O. Kuntze) di Unit Perkebunan Tambi, Wonosobo, Jawa Tengah
} Tea Planting Management (Camelia $\frac{\text { Sinensis (L) O. Kuntze) In Tambi Plantation Unit, Wonosobo, }}{\text { Central Java }}$

\author{
Ajeng Eka Prastiwi dan Adolf Pieter Lontoh* \\ Departemen Agronomi dan Hortikultura, Fakultas Pertanian, Institut Pertanian Bogor \\ (Bogor Agricultural University), Jl. Meranti, Kampus IPB Darmaga, Bogor 16680, Indonesia \\ Telp.\& Faks.62-251-8629353 e-mail agrohort@apps.ipb.ac.id \\ *Penulis Korespondensi : alfpieter1@yahoo.com
}

Disetujui : 21 Mei 2018 / Published Online 2 Januari 2019

\begin{abstract}
The research at Tambi Plantation Unit aims to improve the ability and professionalism in the work process in the field and field technical experience on tea plants and analyze the problems that occur in the field. The special purpose of research is to study the tea-picking management in Tambi Plantation Unit. The method used is direct method and indirect method. The direct method is carried out by following and observing technical activities in the cultivation of tea in the field as well as interview, while indirect method is done by collecting supporting data from the company in the form of management report, archive and literature study. Self-observation of research on specific aspects of tea picking indicates that the height of the quotation field, the diameter of the quotation field, the leaf thickness of the maintenance, the picking quotes, the picking, shoot analysis, the quotation capacity and the labor requirements are in accordance with the standard in the application of Good Agricultural Practices GAP). The results of the quotation analysis still need improvement in the technical activities of picking. Gambung 4 clones grow optimally at an altitude of $1000-1250 \mathrm{~m}$ asl.
\end{abstract}

Keywords: analysis of shoots, leaf maintenance, Gambung 4, Good Agricultural Practices (GAP), picking capacity

\begin{abstract}
ABSTRAK
Kegiatan penelitian di Unit Perkebunan Tambi bertujuan untuk meningkatkan kemampuan dan profesionalisme dalam proses kerja di lapang dan pengalaman teknis lapang pada tanaman teh serta menganalisis permasalahan yang terjadi di lapang. Tujuan khusus dari kegiatan penelitian adalah mempelajari manajemen pemetikan teh yang ada di Unit Perkebunan Tambi. Metode yang digunakan adalah metode langsung dan metode tidak langsung. Metode langsung dilaksanakan dengan mengikuti dan mengamati kegiatan teknis dalam budidaya teh di lapangan serta wawancara, sedangkan metode tidak langsung dilakukan dengan mengumpulkan data pendukung dari perusahaan berupa laporan manajemen, arsip kebun dan studi pustaka. Hasil pengamatan mandiri dari kegiatan penelitian pada aspek khusus pemetikan teh menunjukkan bahwa tinggi bidang petik, diameter bidang petik, tebal daun pemeliharaan, gilir petik, hanca petik, analisis pucuk, kapasitas petik, dan kebutuhan tenaga kerja sudah sesuai dengan standar dalam penerapan Good Agricultural Practices (GAP). Hasil analisis petik masih perlu perbaikan dalam kegiatan teknis pemetikan. Jenis klon Gambung 4 tumbuh optimal pada ketinggian 1000-1250 m dpl.
\end{abstract}

Kata kunci: analisis pucuk, daun pemeliharaan, Gambung 4, Good Agricultural Practices (GAP), kapasitas petik 


\section{PENDAHULUAN}

Teh merupakan tanaman yang berasal dari daerah sub tropis, sehingga sangat cocok dibudidayakan di daerah dataran tinggi. Suhu udara yang cocok bagi tanaman teh adalah antara 13-15 ${ }^{\circ} \mathrm{C}$ dengan kelembaban relatif pada siang hari yaitu $>70 \%$ dan curah hujan tahunan tidak kurang dari $2000 \mathrm{~mm}$. Pekebunan teh di Indonesia berada pada keserasian elevasi yang cukup luas, yaitu sekitar 400-2000 m dpl (Syakir, 2010).

Tanaman teh adalah komoditas yang memiliki peranan cukup penting bagi perekonomian Indonesia. Teh memiliki manfaat sebagai vitamin dan mineral yang dibutuhkan oleh tubuh. Tanaman teh memiliki potensi yang besar dalam menambah devisa negara sebagai komoditas ekspor sesudah minyak dan gas (Syaipullah, 2010). Peluang ekspor dan pasar dalam negeri yang masih cukup besar jika diimbangi dengan peningkatan mutu poduksi serta diversifikasi produk yang disesuaikan dengan kebutuhan konsumen saat ini. Pertanaman teh yang dibudidayakan di Indonesia dibagi menjadi tiga daerah berdasarkan ketinggian tempatnya, yaitu perkebunan teh pada dataran rendah dengan ketinggian sampai dengan $800 \mathrm{~m} \mathrm{dpl}$, dataran sedang dengan ketinggian 800-1.200 m dpl, dan dataran tinggi dengan ketinggian lebih dari 1200 m dpl.

Luasan perkebunan teh Indonesia tahun 2014 mencapai 122.490 ha. Luasan tesebut merupakan luasan perkebunan teh besar yang ada di seluruh wilayah Indonesia. Produktivitas pucuk teh yang dihasilkan di perkebunan teh Indonesia tahun 2015 diperkirakan mencapai 1.1 ton $\mathrm{ha}^{-1}$. Indonesia telah berhasil mengekspor teh sebesar 70840 ton tahun 2013. Nilai ekspor ini terus menurun dari tahun 2005 yang dapat mengekspor 102389 ton (Ditjenbun, 2014). Produksi teh dalam negeri dari tahun ke tahun mengalami fluktuasi tetapi cenderung semakin menurun. Produksi teh ton tahun ${ }^{-1}$ pada tahun 2014 hanya mencapai 142720 ton tahun $^{-1}$. Produksi teh mengalami penurunan sebesar $2.2 \%$ dari tahun sebelumnya yang mencapai 145860 ton tahun ${ }^{-1}$ (BPS, 2015). Fluktuasi produksi teh di Indonesia sangat bergantung dengan proses pemetikan yang dilakukan di lahan produksi. Pemetikan yang menggunakan prosedur yang tepat saat pemetikan akan menghasilkan poduksi pucuk teh yang maksimal. Teknik pemetikan menentukan kualitas pucuk teh yang dihasilkan.

Pucuk teh yang bermutu tinggi merupakan bahan baku untuk menghasilkan teh dengan kualitas yang baik. Kualitas pucuk teh sangat dipengaruhi oleh beberapa faktor, di antaranya sistem pemetikan, gilir petik, hanca petik, kapasitas petik, organisasi dan ketenagakerjaan pemetikan, serta sarana panen dan transportasi (Setyamidjaja, 2000). Teh yang berkualitas baik adalah teh yang diolah dari bahan baku yang memiliki mutu tinggi serta pengolahan yang benar. Produk teh yang berkualitas baik akan meningkatkan minat dari konsumen. Salah satu cara adalah memperbaiki sistem pemetikan yang lebih efisien sehingga dapat mencapai hasil yang maksimal (Nazaruddin dan Paimin, 1993). Tujuan khusus dari kegiatan penelitian adalah mempelajari manajemen pemetikan teh yang ada di Unit Perkebunan Tambi, Wonosobo, Jawa Tengah.

\section{BAHAN DAN METODE}

Kegiatan penelitian dilaksanakan di Unit Perkebunan Tambi, Wonosobo, Jawa Tengah pada tanggal 6 Februari - 5 Juni 2017. Kegiatan penelitian dilaksanakan dengan dua metode, yaitu metode langsung dan metode tidak langsung. Metode langsung dilaksanakan dengan melakukan pengamatan secara langsung di lapang serta mengikuti semua kegiatan teknis budidaya tanaman teh mulai dari pembibitan sampai dengan pengolahan hasil pemetikan pucuk teh. Metode tidak langsung dilaksanakan dengan memperoleh dan mempelajari data sekunder berupa arsip kebun dan laporan dari perusahaan.

Pengamatan dilakukan dengan menggunakan data primer dan data sekunder. Data primer diperoleh dengan melakukan kegiatan praktik kerja secara langsung serta melakukan diskusi dan wawancara dengan beberapa staf dan karyawan kebun. Data sekunder diperoleh dengan mengumpulkan laporan manajemen (bulanan, triwulanan, semesteran, dan tahunan) serta dokumentasi lapang. Peubah yang diamati selama kegiatan penelitian terkait dengan manajeman pemetikan teh meliputi tinggi bidang petik, diameter bidang petik dan tebal daun pemeliharaan dengan metode memilih 10 tanaman contoh dengan umur tanaman yang berbeda yaitu 1-4 tahun setelah pangkas pada dua blok.

Pengukuran bidang petik dilakukan dengan cara mengukur tinggi tanaman dari permukaan tanah hingga pada bidang petik. Diameter bidang petik dilakukan dengan mengukur lebar bidang petik dari Utara-Selatan dan Barat-Timur lalu dijumlah dan dirata-rata. Pengukuran tebal daun pemeliharaan dilakukan dengan mengukur tebal daun (4-5 helai daun dari bidang petik). Pengamatan gilir petik dilakukan dengan cara wawancara dengan pembimbing petik (Mandor) maupun kepala sub bagian kebun. Pengamatan dilakukan untuk mengetahui selang waktu antara 
satu pemetikan dengan pemetikan berikutnya pada blok contoh yang sama dan dinyatakan dalam satuan hari. Peubah yang diamati selanjutnya adalah hanca petik, pengukuran hanca petik dengan melihat data sekunder luas area tanaman menghasilkan yang ada di kebun lalu dibagi dengan hasil gilir petik yang telah dilakukan di lapang. Pengamatan kapasitas petik dilakukan berdasarkan umur pekerja dan lamanya bekerja.

Analisis petikan dianalisis berdasarkan data primer dan sekunder. Data primer diperoleh dengan mengambil masing-masing sampel pucuk satu genggam (dari 10 pemetik, pada satu mandor) yang dicampur menjadi satu kemudian diambil 250 gram untuk dipisahkan sesuai jenis pucuk (rumus petik) dan ditimbang.

Satuan yang digunakan adalah persen (\%) dengan membandingkan masing-masing kelompok pucuk. Analisis pucuk, dilakukan dengan mengambil sampel sebanyak 250 gram pada masing-masing blok. Sampel dikelompokkkan menjadi pucuk yang memenuhi syarat (MS) dan pucuk yang tidak memenuhi syarat (TMS). Pucuk yang memenuhi syarat dibedakan berdasarkan mutu teh sesuai standar perusahaan. Kebutuhan tenaga pemetik dilakukan dengan membandingkan hasil perhitungan dengan jumlah tenaga kerja secara riil yang ada di lapangan. Pengamatan selanjutnya adalah mengamati daya adaptasi klon Gambung 4. Pengamatan dilakukan pada dua blok dengan ketinggian yang berbeda dan pada tahun pangkas II dan III. Peubah yang diamati dari daya adaptasi klon Gambung 4 adalah produksi empat tahun terakhir, tinggi bidang petik, diameter bidang petik, dan tebal daun pemeliharaan.

Sebagian data yang diperoleh dianalisis dengan menggunakan uji t-student. Nilai beda nyata apabila $t_{\text {hit }}>t_{\text {tabel }}$ dan tidak berbeda nyata apabila $t_{\text {hit }}<t_{\text {tabel }}$ diperoleh dari nilai sebaran $t$ pada taraf $5 \%$ dan $\mathrm{db}\left(\mathrm{n}_{1}+\mathrm{n}_{2}-2\right)$ (Walpole, 1995). Sedangkan data primer dan sekunder dianalisis secara deskriptif dan rataan.

\section{HASIL DAN PEMBAHASAN}

Kualitas dan kuantitas dari pucuk teh yang dihasilkan ditentukan oleh beberapa faktor, yaitu tinggi bidang petik, diameter bidang petik, tebal daun pemeliharaan, jenis klon yang digunakan, gilir petik, hanca petik, analisis petik, analisis pucuk, kapasitas pemetik jenis klon, dan kebijakan dari kebun.

\section{Tinggi Bidang Petik}

Tinggi bidang petik merupakan alah satu penentu kualitas dan kuantitas dari pucuk yang telah dipetik. Diagram tinggi bidang petik di Unit Perkebunan Tambi dapat dilihat pada Gambar 1.

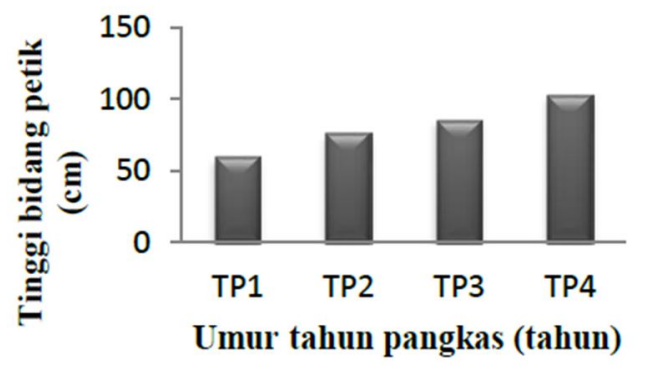

Gambar 1. Tinggi bidang petik berdasarkan tahun pangkas di UP Tambi tahun 2017

Hasil pengamatan meenunjukkan bahwa tinggi bidang petik pada tahun pangkas 4 dikategorikan cukup ideal yaitu dengan tinggi $102.73 \mathrm{~cm}$. Kegiatan pemetikan masih dapat dilakukan dengan cukup mudah karena ketinggian tanaman tidak terlalu tinggi bagi pemetik. Ketinggian bidang petik yang sudah tidak ergonomis bagi pemetik adalah 120-140 cm (Puslitbangtan, 2010). Tinggi ideal dari tanaman teh tahun pangkas 4 adalah 80-110 $\mathrm{cm}$ (Johan dan Dalimoenthe, 2009). Tinggi bidang petik dipengaruhi oleh beberapa faktor di antaranya jenis klon, ketinggian tempat dan kesehatan tanaman.

\section{Diameter Bidang Petik}

Diameter bidang petik di Unit Perkebunan Tambi berkorelasi positif dengan pertambahan umur pangkas. Semakin tinggi umur pangkas, maka diameter bidang petik semakin lebar. Tabel diameter bidang petik di Unit Perkebunan Tambi berdasarkan tahun pangkas pada tahun 2017 dapat dilihat di Tabel 1.

Tabel 1. Diameter bidang petik di UP Tambi berdasarkan tahun pangkas pada tahun 2017

\begin{tabular}{lcccc}
\hline \multirow{2}{*}{ Blok } & \multicolumn{4}{c}{$\begin{array}{c}\text { Diameter Bidang Petik pada Umur } \\
\text { setelah Pemangkasan (tahun) }\end{array}$} \\
\hline & TP1 & TP2 & TP3 & TP4 \\
& $\ldots \ldots \ldots \ldots \ldots \ldots \ldots \ldots(\mathrm{cm})$ & $\ldots \ldots \ldots \ldots \ldots \ldots \ldots \ldots \ldots \ldots \ldots$ \\
Pemandangan & 91.10 & 91.20 & 91.50 & 123.60 \\
Taman & 73.05 & 82.69 & 96.20 & 102.80 \\
Panama & 81.35 & 92.89 & 101.00 & 115.60 \\
Kelunakan & 72.30 & 78.70 & 83.85 & 103.86 \\
Tanah Hijau & 79.45 & 86.37 & 93.14 & 111.47 \\
\hline Rata-rata & 91.10 & 91.20 & 91.50 & 123.60 \\
\hline
\end{tabular}

Hasil pengamatan diameter bidang petik di Unit Perkebunan Tambi menunjukkan bahwa semakin tinggi umur pangkas tanaman teh maka diameter tanaman akan semakin lebar. Lebar diameter bidang petik dipengaruhi oleh tanaman asal, antara tanaman seedling, dan hasil dari stek memiliki diameter bidang petik yang berbeda. Diameter bidang petik tanaman seedling memiliki ukuran diameter yang lebih lebar dibandingkan 
dengan tanaman yang berasal dari bahan stek. Lebar diameter bidang petik juga dipengaruhi oleh jenis klon, kesehatan tanaman, dan umur pangkas.

\section{Tebal Daun Pemeliharaan}

Tebal daun pemeliharaan dari tanaman teh yaitu semakin tinggi umur pangkasan, maka tebal daun pemeliharaan akan semakin tebal. Rata-rata tebal daun pemeliharaan di Unit Perkebunan Tambi adalah $25 \mathrm{~cm}$ dari permukaan bidang petik. Grafik tebal daun pemeliharaan di Unit Perkebunan Tambi berdasarkan tahun pangkas pada tahun 2017 dapat dilihat di Gambar 2.

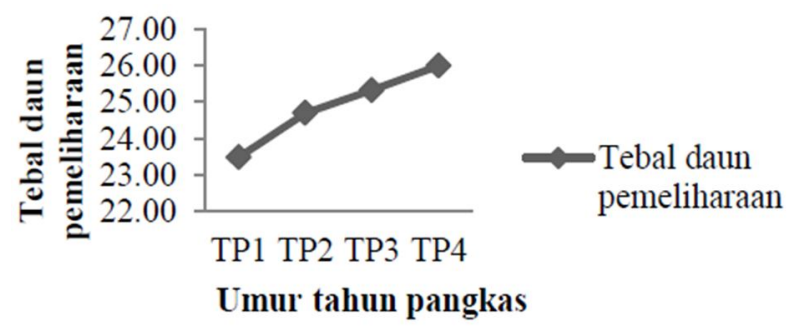

Gambar 2. Tebal daun pemeliharaan di UP Tambi berdasarkan tahun pangkas pada tahun 2017

Hasil pengamatan (Gambar 2), tebal daun pemeliharaan pada setiap umur tahun pangkas di Unit Perkebunan Tambi menunjukkan tebal daun pemeliharaan lebih dari $20 \mathrm{~cm}$. Tebal daun pemeliharaan tertinggi adalah pada tahun pangkas IV yaitu $26 \mathrm{~cm}$. Menurut Johan (2005) fungsi daun pemeliharaan akan optimal jika ketebalan maksimal daun pemeliharaan adalah $20 \mathrm{~cm}$. Jika tanaman teh memiliki tebal daun lebih dari $20 \mathrm{~cm}$, maka fotosintat yang sampai ke pucuk dan akar tidak akan optimal, karena fotosintat juga akan terbagi ke dalam daun pemeliharaan. Upaya yang dapat dilakukan adalah dengan memangkas atau menurunkan bidang petik saat kegiatan pemeliharaan. Penggunaan mesin petik sebagai mekanisasi kegiaatan pemetikan adalah salah satu upaya dalam menekan jumlah kehilangan zat pati pada daun, karena hasil petikan lebih rata dan halus dibandingkan dengan menggunakan gunting petik (Puslitbangbun, 2010).

\section{Gilir Petik}

Gilir petik yang ditetapkan Unit Perkebunan Tambi untuk setiap blok adalah 30-60 hari. Pengamatan gilr petik di Unit Perkebunan Tambi pada periode bulan Januari-Mei dapat dilihat pada Tabel 2. Rata-rata gilir petik di Unit Perkebunan Tambi adalah 55 hari.

Hasil pengamatan gilir petik di Unit Perkebunan Tambi pada periode bulan JanuariMei (Tabel 2) menunjukkan bahwa ketinggian tempat sangat berpengaruh pada panjang pendeknya gilir petik. Blok Pemandangan 2
Tabel 2. Gilir petik di UP Tambi periode JanuariMei 2017

\begin{tabular}{lcccc}
\hline Blok & $\begin{array}{c}\text { Ketinggian } \\
\text { Tempat } \\
(\mathrm{m} \mathrm{dpl})\end{array}$ & $\begin{array}{c}\text { Luas } \\
\text { Lahan } \\
\left(\mathrm{m}^{2}\right)\end{array}$ & $\begin{array}{c}\text { Luas Areal } \\
\text { yang dipetik } \\
\text { hari }^{-1} \text { (ha) }\end{array}$ & $\begin{array}{c}\text { Gilir } \\
\text { Petik } \\
\text { (hari) }\end{array}$ \\
\hline Pemandangan 1 & $1700-2100$ & 38.91 & 0.64 & 61 \\
Pemandangan 2 & $1700-2.100$ & 29.93 & 0.40 & 74 \\
Taman & $1300-1500$ & 58.69 & 1.28 & 46 \\
Panama & $1250-1500$ & 65.20 & 1.19 & 55 \\
Tanah Hijau & $1000-1250$ & 39.38 & 1.01 & 39 \\
\hline Rata-rata & & 46.42 & 0.90 & 55 \\
\hline
\end{tabular}

memiliki siklus gilir petik yang paling panjang karena berada pada ketinggian 1700-2100 m dpl. Blok Tanah Hijau memiliki siklus gilir petik yang paling pendek karena berada pada ketinggian 1000-1250 m dpl. Teknis pemetikan di Unit Perkebunan Tambi adalah dengan menggunakan gunting petik dengan gilir petik adalah tipe siklus panjang. Menurut Johan dan Sriyadi (2005) pemetikan dengan menggunakan gunting petik dan siklus petik panjang dapat menggali potensi hasil yang optimal. klon Gambung 7 memiliki potensi hasil mencapai di atas $5000 \mathrm{~kg}$ kering ha ${ }^{-1}$ tahun $^{-1}$. Faktor-faktor yang mempengaruhi panjang pendeknya gilir petik adalah ketinggian tempat, iklim, umur pangkas tanaman, kesuburan tanah dan teknis pemetikan oleh pemetik.

\section{Hanca Petik}

Hanca petik setiap blok di Unit Perkebunan Tambi berbeda-beda. Besar kecilnya hanca petik ditentukan oleh kondisi pucuk di kebun dan topografi masing-masing kebun. Hanca petik di Unit Perkebunan Tambi pada periode Januari-Mei 2017 dapat dilihat di Tabel 3.

Tabel 3. Hanca petik di UP Tambi periode Januari-Mei 2017

\begin{tabular}{lcccc}
\hline Blok & $\begin{array}{c}\text { Luas } \\
\text { Lahan } \\
\text { (ha) }\end{array}$ & $\begin{array}{c}\text { Gilir } \\
\text { Petik } \\
\text { (hari) }\end{array}$ & $\begin{array}{c}\text { Jumlah } \\
\text { Pemetik } \\
\text { (orang) }\end{array}$ & $\begin{array}{c}\text { Hanca per } \\
\text { Pemetik (ha } \\
\text { HK }^{-1} \text { ) }\end{array}$ \\
\hline Pemandangan 1 & 38.91 & 61 & 16 & 0.64 \\
Pemandangan 2 & 29.93 & 74 & 28 & 0.40 \\
Taman & 58.69 & 46 & 36 & 1.28 \\
Panama & 65.20 & 55 & 43 & 1.19 \\
Tanah Hijau & 39.38 & 39 & 25 & 1.01 \\
\hline Rata-rata & 46.42 & 55 & 28 & 0.90 \\
\hline
\end{tabular}

Hanca petik sangat dipengaruhi oleh kondisi pucuk, topografi dan jumlah tenaga pemetik. Ketika kondisi pucuk sedang tinggi, maka hanca petik bagi pemetik akan berkurang. Kemiringan lahan juga sangat berpengaruh terhadap hanca petik. Semakin miring lahan maka kegiatan pemetikan akan lebih sulit dibandingkan dengan lahan yang lebih datar. Kegiatan pemetikan yang dilakukan di lahan miring akan 
memiliki hanca petik yang lebih kecil. Hanca petik juga dipengaruhi oleh jumlah tenaga kerja yang bekerja setiap hari. Hanca petik di Unit Perkebunan Tambi pada periode Januari-Mei 2017 (Tabel 3) lebih tinggi dibandingkan dengan pada periode Januari-Mei 2015 yaitu 0.30 ha dan hanca per pemetik 0.03 ha (Zamroni, 2015). Hal ini disebabkan Unit Perkebunan Tambi saat ini sedang berorientasi pada peningkatan produksi per tahunnya. Hanca yang semakin luas diharapkan akan meningkatan produksi pucuk teh setiap tahunnya sehingga keuntungan yang didapat perusahaan akan meningkat.

\section{Analisis Petik}

Pengamatan analisis petik dilakukan dengan mengambil sampel dari sepuluh pemetik dari setiap blok dan diambil 250 gram untuk dianalisis. Hasil pengamatan analisis petik di Unit Perkebunan Tambi adalah petikan halus $2.50 \%$, petikan medium $40.10 \%$, petikan kasar $21.50 \%$, dan petikan rusak $35.90 \%$. Tabel hasil analisis pucuk di Unit Perkebunan Tambi dapat dilihat pada Tabel 4.

Tabel 4. Analisis petik di UP Tambi tahun 2017

\begin{tabular}{|c|c|c|c|c|}
\hline \multirow[t]{2}{*}{ Blok } & \multicolumn{4}{|c|}{ Komposisi pucuk (\%) } \\
\hline & $\begin{array}{c}\text { Petikan } \\
\text { halus }^{\mathrm{a}}\end{array}$ & $\begin{array}{l}\text { Petikan } \\
\text { medium }^{\mathrm{b}}\end{array}$ & $\begin{array}{c}\text { Petikan } \\
\text { kasar }^{\mathrm{c}}\end{array}$ & $\begin{array}{c}\text { Petikan } \\
\text { rusak }^{\mathrm{d}}\end{array}$ \\
\hline Pemandangan 1 & 1.60 & 38.00 & 19.60 & 40.80 \\
\hline Pemandang & 4.00 & 43.20 & 23.20 & 29.60 \\
\hline Taman & 2.00 & 38.80 & 20.80 & 38.40 \\
\hline Panar & 3.20 & 44.00 & 21.60 & 31.20 \\
\hline Tanah Hijau & 1.60 & 36.40 & 22.40 & 39.60 \\
\hline Rata-rata & 2.48 & 40.08 & 21.52 & 35.92 \\
\hline
\end{tabular}

Ketentuan: Petikan halus $<5 \%$, dan petikan medium minimal 50\% (Unit Perkebunan Tambi 2017)

Keterangan: ${ }^{\mathrm{a}}$ Petikan halus $=\mathrm{p}+1$ dan $\mathrm{p}+2 \mathrm{~m}$

${ }^{\mathrm{b}}$ Petikan medium $==\mathrm{p}+2, \mathrm{p}+3 \mathrm{~m}, \mathrm{p}+3$, $\mathrm{b}+1 \mathrm{~m}, \mathrm{~b}+2 \mathrm{~m}$ dan $\mathrm{b}+3 \mathrm{~m}$

${ }^{c}$ Petikan kasar $=p+4$ atau lebih, $\mathrm{b}+1 \mathrm{t}$, $\mathrm{b}+2 \mathrm{t}, \mathrm{b}+3 \mathrm{t}$ dan $\mathrm{b}+4 \mathrm{t}$ atau lebih

${ }^{\mathrm{d}}$ Petikan rusak $=$ daun lembaran dan tangkai
Analisis petik adalah memisahkan pucuk berdasarkan rumus petiknya. Umumnya jenis petikan yang diinginkan adalah jenis petikan medium. Komposisi petikan medium adalah minimal $70 \%$ petikan medium, maksimal $10 \%$ petikan halus dan $20 \%$ petikan kasar (PPTK, 2010). Unit Perkebunan Tambi memiliki kebijakan sendiri untuk analisis petik. Persentase petikan halus dibawah $5 \%$ dan petikan medium minimal $50 \%$. Tinggi rendah hasil analisis petik dipengaruhi oleh beberapa faktor, yaitu teknik pemetikan, kesehatan tanaman, gilir petik dan proses pengiriman pucuk ke pabrik pengolahan. Hasil pengamatan analisis petik yang dilakukan di Unit Perkebunan Tambi (Tabel 4) menujukkan nilai analisis petik masih di bawah $50 \%$, yaitu 40.08\%. Persentase petikan rusak masih cukup tinggi yaitu $35.92 \%$. Artinya faktor yang perlu dibenahi adalah dari teknis pemetikan dan pengangkutan pucuk dari kebun ke pabrik, sehingga dapat meminimalisir kerusakan pucuk dan menjaga kualitas pucuk.

\section{Analisis Pucuk}

Analisis pucuk diamati dengan mengambil sampel dari setiap blok dan dipisahkan berdasarkan pucuk memenuhi syarat dan tidak memenuhi syarat dan dihitung persentasenya. Hasil analisis pucuk di Unit Perkebunan Tambi pada bulan Januari sampai dengan April adalah $50.35 \%$ untuk pucuk yang memenuhi syarat dan $49.65 \%$ untuk pucuk yang tidak memenuhi syarat. Tabel analisis pucuk Unit Perkebunan Tambi dapat dilihat di Tabel 5.

Analisis pucuk dilakukan untuk melihat persentase pucuk muda dan pucuk tua yang telah terpetik. Analisis pucuk juga menentukan pucuk yang memenuhi syarat (MS) dan tidak memenuhi syarat (TMS) untuk diolah dan dinyatakan dalam persen. Nilai analisis pucuk Unit Perkebunan Tambi pada periode Januari-April sudah mencapai

Tabel 5. Analisis pucuk UP Tambi periode Januari-April 2017

\begin{tabular}{|c|c|c|c|c|c|c|c|c|c|c|}
\hline \multirow[t]{2}{*}{ Blok } & \multicolumn{2}{|c|}{ Januari } & \multicolumn{2}{|c|}{ Februari } & \multicolumn{2}{|c|}{ Maret } & \multicolumn{2}{|c|}{ April } & \multicolumn{2}{|c|}{ Mei } \\
\hline & $\mathrm{MS}^{\mathrm{a}}$ & $\mathrm{TMS}^{\mathrm{b}}$ & MS & TMS & MS & TMS & MS & TMS & MS & TMS \\
\hline & & & & & & & & & & -- \\
\hline Taman & 52.7 & 47.3 & 50.7 & 49.3 & 51.7 & 48.3 & 49.6 & 50.5 & 50.1 & 49.9 \\
\hline Pemandangan 1 & 42.2 & 57.8 & 50.4 & 49.6 & 50.2 & 49.8 & 45.3 & 54.7 & 50.4 & 49.6 \\
\hline Pemandangan 2 & 52.7 & 47.3 & 53.5 & 46.5 & 50.2 & 49.8 & 51.0 & 49.0 & 51.1 & 48.9 \\
\hline Panama & 49.0 & 51.0 & 50.3 & 49.7 & 51.8 & 48.2 & 53.9 & 46.1 & 51.4 & 48.6 \\
\hline Tanah Hijau & 50.1 & 49.9 & 46.4 & 53.6 & 48.6 & 51.4 & 48.0 & 52.0 & 49.1 & 50.9 \\
\hline UP Tambi & 50.1 & 49.9 & 50.5 & 49.5 & 50.9 & 49.2 & 49.9 & 50.1 & 50.5 & 49.5 \\
\hline Rata-rata & 49.3 & 50.7 & 50.3 & 49.7 & 50.5 & 49.5 & 49.6 & 50.4 & 50.4 & 49.6 \\
\hline
\end{tabular}

Keterangan : ${ }^{a}$ Pucuk memenuhi syarat (MS) : $p+1, p+2, p+3, b+1 m, b+2 m, b+3 m$

${ }^{\mathrm{b}}$ Pucuk tidak memenuhi syarat (TMS) $: \mathrm{p}+4, \mathrm{p}+5, \mathrm{~b}+(1-5) \mathrm{t}$ 
$50.34 \%$. Berbeda dengan hasil pengamatan yang dilakukan Pratiwi (2011), hasil analisis pucuk di Unit Perkebunan Tanjungsari hanya $44.08 \%$ dengan standar perusahaan 55\%. Hal ini disebabkan oleh masih tingginya persentase petikan kasar dan rusak, teknik pemetikan yang kurang baik, banyaknya serangan hama dan penyakit yang dapat menghambat pertumbuhan pucuk, serta pengelolaan pucuk dari kebun ke pabrik yang kurang baik. Analisis pucuk di Unit Perkebunan Tambi cukup konsisten. Hasil pengamatan Zamroni (2015) menujukkan analisis pucuk pada periode Januari-Mei 2015 adalah $50.02 \%$.

\section{Kapasitas Petik}

Standar kapasitas petik di Unit Perkebunan Tambi adalah $80 \mathrm{~kg}$ hari $^{-1}$. Rata-rata kapasitas pemetik di Unit Perkebunan Tambi pada tahun 2016 adalah $83.75 \mathrm{~kg}$ hari $^{-1}$ setiap pemetik. Kapasitas pemetik berdasarkan umur pemetik di Unit Tambi pada setiap blok dapat dilihat di Tabel 6.

Tabel 6. Kapasitas pemetik berdasarkan umur pemetik di UP Tambi periode JanuariMei 2017

\begin{tabular}{ccc}
\hline Umur (tahun) & $\begin{array}{c}\text { Jumlah sampel } \\
\text { (orang) }\end{array}$ & $\begin{array}{c}\text { Kapasitas petik } \\
\left(\mathrm{kg} \mathrm{HK}^{-1}\right)\end{array}$ \\
\hline $20-40$ & 10 & $142.63 \mathrm{a}$ \\
$41-55$ & 10 & $139.94 \mathrm{a}$ \\
\hline
\end{tabular}

Keterangan : Angka-angka yang diikuti huruf yang sama pada kolom yang sama menunjukkan nilai tidak berbeda nyata berdasarkan uji $t$-student dengan taraf nyata $5 \%$.

Hasil pengamatan kapasitas petik di Unit Perkebunan Tambi dilakukan berdasarkan pengalaman kerja sebagai pemetik. Kapasitas pemetik berdasarkan lama bekerja dapat dilihat di Tabel 7. Pada Tabel 7 ditunjukkan bahwa tidak memiliki perbedaan nyata pada kapasitas pemetik berdasarkan lama bekerja sebagai pemetik. Data ditunjukkan dengan angka dan diikuti huruf yang sama pada kolom rata-rata kapasitas pemetik.

Tabel 7. Kapasitas pemetik berdasakan lama kerja pemetik di UP Tambi tahun 2017

\begin{tabular}{ccc}
\hline $\begin{array}{c}\text { Lama } \\
\text { bekerja(tahun) }\end{array}$ & $\begin{array}{c}\text { Jumlah sampel } \\
\text { (orang) }\end{array}$ & $\begin{array}{c}\text { Kapasitas petik } \\
\left(\mathrm{kg} \mathrm{HK}^{-1}\right)\end{array}$ \\
\hline$<15$ & 10 & $135.05 \mathrm{a}$ \\
$>15$ & 10 & $130.86 \mathrm{a}$ \\
\hline
\end{tabular}

Keterangan : Angka-angka yang diikuti huruf yang sama pada kolom yang sama menunjukkan nilai tidak berbeda nyata berdasarkan uji $t$-student dengan taraf nyata $5 \%$.
Hasil pengamatan menunjukkan bahwa kapasitas petik tidak dipengaruhi oleh umur dan lama bekerja seorang pemetik. Kapasitas petik ditentukan oleh kondisi pucuk di lapang, keterampilan pemetik, jumlah pokok tanaman teh, umur tahun pangkas, cuaca dan topografi kebun. Kondisi kebun yang sehat akan menghasilkan produksi pucuk teh yang maksimal. Hasil pengamatan menunjukkan bahwa kapasitas pemetik tidak dipengaruhi oleh umur pemetik dan lama bekerja seorang pemetik.

\section{Kebutuhan Tenaga Kerja}

Perhitungan jumlah tenaga kerja sangat penting untuk dilakukan dengan tujuan adalah untuk mengoptimalkan kegiatan pemetikan secara efektif dan efisien. Pada Tabel 8 ditunjukkan hasil perhitungan tenaga kerja pemetik dengan pengamatan jumlah tenaga kerja pemetik di lapangan. Hasil perhitungan dapat digunakan untuk perbandingan jumlah tenaga kerja yang dibutuhkan oleh masing-masing blok sesuai dengan luasan dan produksi pucuk basah per hektar per tahun.

Tabel 8. Kebutuhan tenaga kerja pemetik di UP Tambi

\begin{tabular}{|c|c|c|c|c|}
\hline \multirow{2}{*}{ Blok } & \multirow{2}{*}{$\begin{array}{l}\text { Luas } \\
\text { (ha) }\end{array}$} & \multirow{2}{*}{$\begin{array}{c}\text { Rencana } \\
\text { pucuk } \\
\left(\mathrm{kg} \mathrm{tahun}^{-1}\right)\end{array}$} & \multicolumn{2}{|c|}{$\begin{array}{l}\text { Jumlah tenaga kerja } \\
\text { (orang) }\end{array}$} \\
\hline & & & $\begin{array}{c}\text { Hasil } \\
\text { perhitungan }\end{array}$ & Lapangan \\
\hline Pemandangan 1 & 58.69 & 939.000 & 42 & 43 \\
\hline Pemandangan 2 & 38.91 & 618.000 & 28 & 16 \\
\hline Taman & 29.93 & 406.000 & 18 & 28 \\
\hline Panama & 65.2 & 944.000 & 42 & 43 \\
\hline Tanah Hijau & 39.38 & 581.000 & 26 & 25 \\
\hline Jumlah & 232.11 & 3.488 .000 & 157 & 148 \\
\hline
\end{tabular}

Perhitungan kebutuhan tenaga petik sangat penting dalam perencanaan kegiatan budi daya tanaman teh. Tenaga petik disesuaikan dengan luasan area yang dibudidayakan. Unit Perkebunan Tambi memiliki jumlah tenaga petik yang berbeda-beda untuk setiap blok. Blok Taman dan Panama memiliki jumlah pemetik yang paling banyak dibandingkan dengan blok lain karena memiliki lahan yang lebih luas. Hasil perhitungan menunjukkan kebutuhan tenaga pemetik di Unit Perkebunan Tambi sudah cukup sesuai, yaitu pada Blok Pemandangan 2, Blok Taman, Blok Panama dan Blok Tanah Hijau, sedangkan pada Blok Pemandangan 1 masih memerlukan tambahan tenaga kerja (Tabel 8). Penambahan tenaga pemetik di Unit Perkebunan Tambi masih sulit untuk dilakukan karena faktor kurangnya minat masyarakat untuk bekerja sebagai pemetik. Unit 
Pekebunan Tambi melakukan upaya dalam menanggulangi masalah tersebut dengan melakukan mekanisasi. Mekanisasi budi daya yang dilakukan menggunkan mesin petik sebagai alat untuk mengambil hasil pucuk yang ada di kebun.

\section{Daya Adaptasi Gambung 4}

Jenis klon dan ketinggian tempat adalah faktor-faktor yang dapat mempengaruhi tinggi rendahnya produktivitas Klon. Gambung 4 merupakan salah satu klon yang banyak ditanam di Unit Perkebunan Tambi. Pada Tabel 9 dan 10 adalah hasil pengamatan daya adaptasi klon Gambung 4 pada dua blok dengan ketinggian yang berbeda, yaitu di Blok Pemandangan 1 dengan ketinggian di atas $1700 \mathrm{~m}$ dpl dan Blok Tanah Hijau dengan ketinggian di atas $1000 \mathrm{~m}$ dpl pada umur tahun pangkas 2 dan 3 .

Tabel 9. Daya adaptasi klon Gambung 4 pada umur tahun pangkas II

\begin{tabular}{lcc}
\hline \multirow{2}{*}{ Variabel } & \multicolumn{2}{c}{ Blok } \\
\cline { 2 - 3 } & Pemandangan 1 & Tanah Hijau \\
\hline Tinggi & $76.10 \mathrm{a}$ & $70.80 \mathrm{~b}$ \\
Diameter & $82.45 \mathrm{a}$ & $78.70 \mathrm{a}$ \\
Tebal daun & $24.00 \mathrm{a}$ & $25.00 \mathrm{a}$ \\
pemeliharaan & & \\
\hline
\end{tabular}

Keterangan : Angka-angka yang diikuti huruf yang sama pada kolom yang sama menunjukkan nilai tidak berbeda nyata. Angka-angka yang diikuti huruf yang berbeda menunjukkan nilai yang berbeda nyata berdasarkan uji $t$-student dengan taraf nyata $5 \%$.

Tabel 10. Daya adaptasi klon Gambung 4 pada umur tahun pangkas III

\begin{tabular}{lcc}
\hline \multirow{2}{*}{ Variabel } & \multicolumn{2}{c}{ Blok } \\
\cline { 2 - 3 } & Pemandangan 1 & Tanah Hijau \\
\hline Tinggi & $82.10 \mathrm{a}$ & $91.20 \mathrm{~b}$ \\
Diameter & $91.75 \mathrm{a}$ & $79.85 \mathrm{~b}$ \\
Tebal daun & $22.00 \mathrm{a}$ & $24.00 \mathrm{~b}$ \\
pemeliharaan & & \\
\hline
\end{tabular}

Keterangan : Angka-angka yang diikuti huruf yang berbeda pada kolom yang sama menunjukkan nilai berbeda nyata berdasarkan uji $t$-student dengan taraf nyata $5 \%$.

Klon Gambung 4 merupakan jenis klon tanaman teh yang memiliki adaptasi yang baik di ketinggian rendah sampai dengan yang tinggi. Gambung 4 memiliki daya adaptasi yang cukup baik jika diperbanyak dengan menggunakan stek daun (Mahfludoh, 2008). Hasil pengamatan menunjukkan bahwa pertumbuhan optimal klon Gambung 4 adalah pada ketinggian 1000-1250 m dpl di Blok Tanah Hijau. Daya adaptasi terbaik dari pengamatan menunjukkan bahwa klon
Gambung 4 akan memiliki hasil yang optimal jika ditanam didaerah dengan dengan ketinggian 1000$1250 \mathrm{~m}$ dpl. Produktivitas pucuk optimal yang dicapai klon Gambung 4 pada tahun pangkas 3 yaitu sebesar $18641 \mathrm{~kg} \mathrm{ha}^{-1}$ tahun $^{-1}$ di Blok Tanah Hijau dengan ketinggian 1000-1250 m dpl. Produksi tersebut adalah hasil produksi rata-rata dari tahun 2013-2016.

\section{KESIMPULAN}

Tinggi bidang petik tanaman teh pada tahun pangkas 1-4 berturut-turut adalah $59.53 \mathrm{~cm} ; 76.08$ $\mathrm{cm} ; 85.33 \mathrm{~cm}$ dan $102.73 \mathrm{~cm}$. Diameter bidang petik rata-rata pada tahun pangkas 1-4 adalah $79.45 \mathrm{~cm} ; 86.37 \mathrm{~cm} ; 93.14 \mathrm{~cm}$ dan $111.47 \mathrm{~cm}$. Kapasitas pemetik yang diperoleh masing-masing pemetik sudah memenuhi standar perusahaan yaitu sudah melebihi $80 \mathrm{~kg} \mathrm{HK}^{-1}$. Kapasitas pemetik tidak ditentukan oleh umur pemetik dan lama bekerja seorang pemetik. Gilir petik di Unit Perkebunan Tambi ditentukan oleh beberapa faktor, di antaranya ketinggian tempat, umur pangkas, jenis klon dan topografi. Semakin tinggi tempat maka gilir petik suatu blok semakin panjang. Hanca petik di Unit Perkebunan Tambi menunjukkan luasan yang dipetik setiap harinya seluas 0.9 ha.

Analisis pucuk di Unit Perkebunan Tambi sampai dengan bulan Mei 2017 menghasilkan rata-rata $50.4 \%$ pucuk memenuhi syarat (MS). Analisis petik masih belum menunjukkan hasil yang optimal dengan komposisi petikan halus sebesar $2.48 \%$, petikan medium sebesar $40.08 \%$ petikan kasar sebesar $21.52 \%$ dan petikan rusak sebesar $35.92 \%$. Standar perusahaan yang diterapkan untuk petikan medium adalah sebesar $50 \%$. Perhitungan tenaga kerja dengan pengamatan jumlah tenaga kerja riil di lapang sudah cukup baik, namun pada Blok Taman dan Blok Pemandangan 1 masih membutuhkan tambahan tenaga kerja yang disesuaikan dengan luasan lahan. Jenis klon Gambung 4 memiliki daya adaptasi dalam pertumbuhan dan perkembangan yang optimum pada ketinggian 1000-1250 m dpl.

\section{DAFTAR PUSTAKA}

[BPS] Badan Pusat Statistik. 2015. Produksi tanaman perkebunan menurut propinsi dan jenis tanaman, Indonesia (2012-2014). Badan Pusat Statistik. Jakarta.

[Ditjenbun] Direktorat Jenderal Perkebunan. 2014. Perbanyakan Bahan Tanaman Teh (Camellia sinensis (L) O. Kuntze). Direktorat Jenderal Perkebunan. Jakarta. 
[Puslibangbun] Pusat Penelitian dan Pengembangan Perkebunan. 2010. Budidaya dan Pasca Panen Teh. Badan Penelitian dan Pengembangan Pertanian. Bogor.

[PPTK Gambung] Pusat Penelitian Teh dan Kina Gambung. 2010. Standar Operasi Prosedur Pemetikan. Pusat Penelitian Teh dan Kina Gambung. Bogor.

Johan, M.E. 2005. Pengaruh tinggi pangkasan dan tinggi jendangan terhadap pertumbuhan dan hasil pucuk basah pada tanaman teh asal biji. Bogor. J. Penelitian Teh dan Kina. 8(12) : 43-48.

Johan, M.E., B. Sriyadi. 2005. Pemetikan klon teh seri GMB pada siklus panjang menggunakan gunting. Jurnal Penelitian Teh dan Kina. 8(3) : 72-78.

Johan, M.E.. S.L. Dalimoenthe. 2009. Pemetikan pada Tanaman Teh. PPTK. Bandung.

Mahfudloh, A. 2008. Keberhasilan dan pertumbuhan stek teh (Camellia sinensis (L.) O. Kuntze) Klon GMB 4 dan GMB 7 pada beberapa macam media tanam. [Skripsi]. Institut Pertanian Bogor. Bogor.
Nazaruddin, F. Paimin. 1993. Pembudidayaan dan Pengolahan Teh. PT. Penebar Swadaya, Jakarta.

Pratiwi, I.N. 2011. Analisis pemetikan dan pengaruhnya terhadap mutu pucuk tanaman teh (Camellia sinensis (L.) O. Kuntze) di Unit Perkebunann Tanjungsari, PT Tambi, Wonosobo, Jawa Tengah. [Skripsi]. Institut Pertanian Bogor. Bogor.

Setyamidjaja, D. 2000. Budi Daya dan Pengolahan Pasca Panen Tanaman Teh. Kanisius, Yogyakarta.

Syakir, M., D. Allorerung, Z. Poeloengan, Syafaruddin, W. Rumini. 2010. Budidaya Tanaman Teh. Aska Media, Bogor.

Syaipullah, M. 2010. Statistik Teh Indonesia. Badan Pusat Statistik. Jakarta.

Walpole, R.E. 1995. Pengantar Statistika. PT Gramedia Pustaka Utama, Jakarta.

Zamroni, M. 2015. Penerapan good agricultural practices (GAP) pada pemeliharaan tanaman teh menghasilkan (Camellia sinensis (L.) O. Kuntze) dengan aspek khusus pemetikan di Unit Perkebunan Tambi, Wonososbo, Jawa Tengah. [Skripsi]. Institut Pertanian Bogor. Bogor. 